\title{
The Baja 1000 car race and its impact on rural communities
}

\author{
J. Soares ${ }^{1}$, R. Blanco ${ }^{2}$, J. Tapia ${ }^{3}$, J. R. Lerma ${ }^{3}$, E. Inzunza ${ }^{1}$ \\ \& S. Avilés ${ }^{4}$ \\ ${ }^{1}$ Engineering Faculty, Universidad Autónoma de Baja California, Mexico \\ ${ }^{2}$ Institute of Oceanographic Research, \\ Universidad Autónoma de Baja California, Mexico \\ ${ }^{3}$ Science Faculty, Universidad Autónoma de Baja California, Mexico \\ ${ }^{4}$ Secretary of Environmental Protection of the State Government of Baja \\ California, Impact Department in Ensenada, B.C., Mexico
}

\begin{abstract}
The Off-Road Baja 1000 race takes place each year on Mexico's Baja California peninsula through rough terrain. The route changes each year, adding excitement for the participants but causing increased damage to the area. No studies have been made to quantify the environmental or socioeconomic impacts so the profit and loss relationships are unknown. The peninsula particularly possesses natural resources by virtue of its beauty, uniqueness and delicacy, establishing two great protected areas: Valle de los Cirios in Baja California State and El Vizcaíno in Baja California Sur State. This study reviews the paths covered by the Baja 1000 races of 2005 and 2006 using GIS. Analyses of the ecological footprint left by the motorcycles and cars show the identification of various impacts to the natural environment, such as ecosystem fragmentation, deforestation of botanical species, animal mortality and terrain erosion, as well as garbage left by the race spectators along diverse sites directly affecting the soil, groundwater table, flora and fauna. Recommendations from this study include the need to control the OffRoad races by means of an Official Norm that regulates these activities and to offer environmental education to the community to make them aware of the impacts they are causing.
\end{abstract}

Keywords: ecological footprint, ecosystem fragmentation, protected areas. 


\section{Introduction}

The Baja California Peninsula offers an appealing resting site for nature lovers. It provides attractions such as whale watching, sports fishing, hiking, scuba diving and a unique type of Cactus Species, offering exotic scenery by the sea, as one travels to the south.

The main livelihood of the people living on both Baja California (northern part of Baja California) and Baja California Sur before the 90s was Tourism, but now production plants ('maquiladoras') are taking over the northern part of the peninsula as the world economy is increasingly preventing travellers from enjoying leisure time outside their own countries.

Some events organized for tourists that had become "a classical" in Ensenada, such as "The Chilli Cook off" and most sport fishing events have been cancelled and the State's Tourism Secretary is looking for new ways to attract more tourism, but Mexico's bad reputation due to the drug cartels have impeded tourists from including Baja California in their vacation plans.

Baja California's Off Road races have become a tradition since the 1970s. The first event was Baja 1000 in 1967 starting from the city of Tijuana. Cars, trucks and motorcycles compete in this challenging event. Currently, it starts in Ensenada and crosses the peninsula through the Baja California Sur State ending in the beautiful city of La Paz. This race became so well known that it has attracted competitors from the United States of America, Canada, England, Japan, New Zealand and Italy, as well as Mexican racers. In all, 24 different countries have participated over the years. Other events such as the Off Road Baja 500 and Baja 250 Races are very popular among our neighbours in the United States of America as well as the locals.

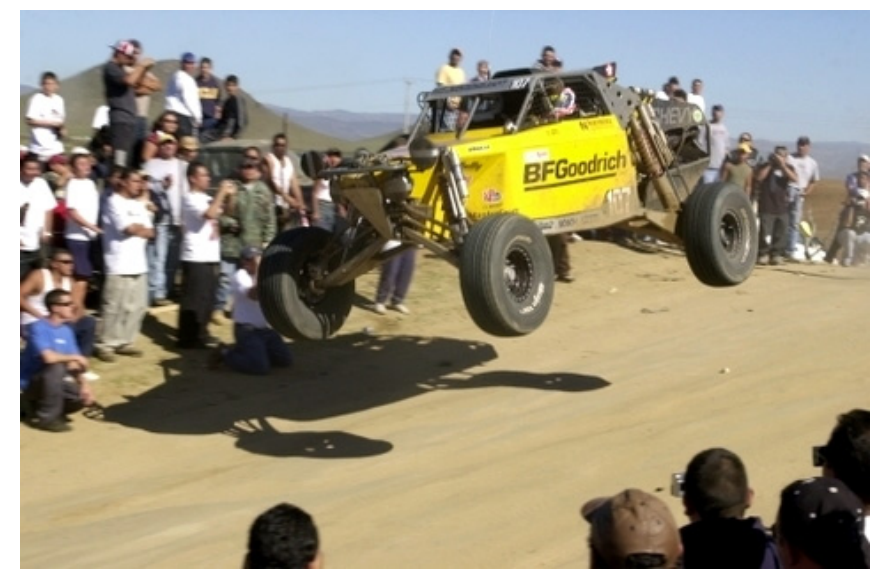

Figure 1: One of the competitors making a jump while spectators are dangerously close to the road. 


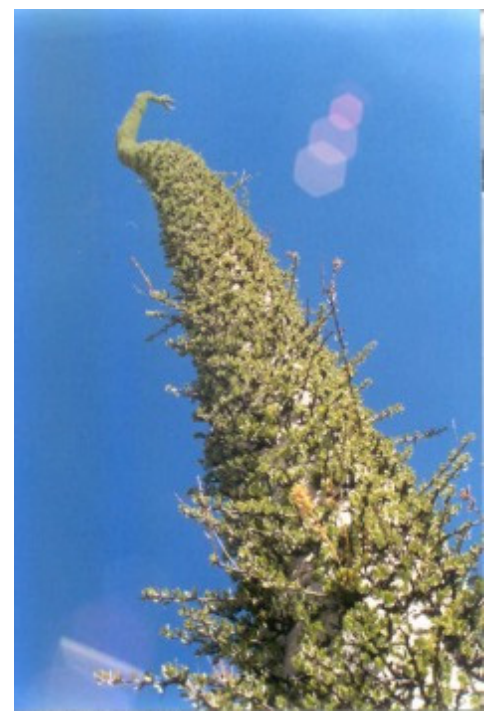

Figure 2: A protected cactus continues to grow on the Valle de los Cirios, in Baja California.

\section{Study area}

Baja California and Baja California Sur are two different states that compose the Peninsula of Baja California. Inland flora and fauna in Baja California are diverse as climate changes from North to South. One can find pines, jojoba, a great diversity of cactus, mountain lions, eagles, coyotes, deer, Bighorn Sheep, etc.

Valle de los Cirios is one of the 125 Natural Areas protected by the Mexican Federation, with an approximate extension of 2,611,000 Has [1]. It is a spectacular desert valley located in the middle of the Baja California Peninsula where Cyrus and Cardons are the common plants observed and protected. Cardons are known to grow an average of 18-20 m (Figure 2).

A study carried out for the Baja California State Tourism Secretariat [2] concludes, in general, that the impacts from the Baja 1000, Baja 500 and Baja 250 races are either negligible, adverse but not significantly, or permanentlyreversible. The authors recommend "that the routes have to be kept on the Coniferous Forest Environmental Unit and the rest of the units should be subject to approval through the Impact Administration and Monitoring Program." The same study suggests preventive measures regarding the contamination by solid and liquid residues and by the repair and maintenance of vehicles; for the prevention and mitigation of the deterioration of the flora and fauna, the authors suggest "to make public a list of the protected species that are inside the zone of influence of the event. This list should be distributed among the participants, the support team and the spectators through massive communication media and through the official race communications." Finally, they suggest that a 
surveillance trip should be executed the day before and the day after the race in order to verify the actions over the zones of integration, the check points and the observation points.

This same study details and stresses the enormous economic advantages for the hotels, restaurants and local shops.

However, Figure 3 shows the route taken by the Baja 1000 participants in 2006, although there is no means of determining if they stayed on the tracks. It is clearly noted that they are crossing the protected area of Valle de los Cirios.

In 2008, 4 major groups of land owners (Tepi, Leandro Valle, Francisco Serrano and Kiliwas) in a letter addressed to Sócrates Bastidas, the Ecology Secretary for the State of Baja California, requested the intervention of the authorities to stop the crossing of the Baja 1000 and Baja 500 participants through their fields. They stated that Off Road Races with no regulations were prohibited in the United States and that we should have similar rules. According to the Group, Native Flora and Fauna are greatly impacted [3].

\section{Analyses}

Land owners were interviewed by the authors with the help of 10 students of the Universidad Autónoma de Baja California and their answers are summarized in the following table.

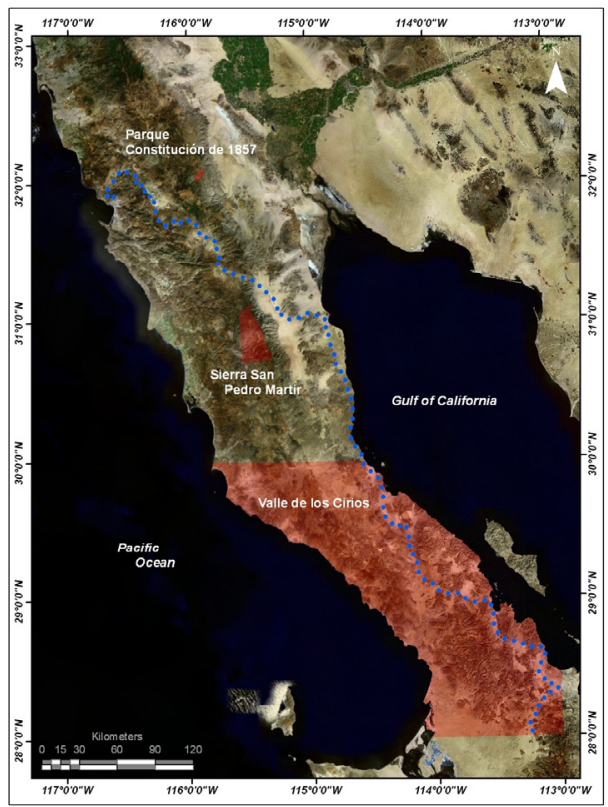

Figure 3: Route taken in 2006 by the competitors of the Baja 1000. 
Table 1: General results of the inquiry made to land owners affected by the Baja 1000 race.

\begin{tabular}{|c|c|c|}
\hline $\begin{array}{c}\text { Economic } \\
\text { compensation for their } \\
\text { loss }\end{array}$ & $35 \%$ sufficient & $65 \%$ not sufficient \\
\hline Trash & & $\begin{array}{c}100 \% \text { Should be taken } \\
\text { care of by the } \\
\text { organizers of the Baja } \\
1000 \text { race }\end{array}$ \\
\hline $\begin{array}{c}\text { Pollution (by fuel, tires, } \\
\text { metal parts) }\end{array}$ & & $100 \%$ Should not occur \\
\hline Noise & $\begin{array}{c}70 \% \text { It's ok. It is just } \\
\text { once a year }\end{array}$ & $\begin{array}{l}30 \% \text { disturbs their } \\
\text { animals }\end{array}$ \\
\hline
\end{tabular}

However, a family living on the Sierra de Ulloa, between Doña Petra's Canyon and San Antonio de las Minas told us that once the Baja race passed through their land, deer that used to graze on their land, never returned.

A few land owners were direct in telling us that they intentionally place an animal or two along the road for the drivers to kill and for them earn some money, in consequence.

In addition, mating of the Bighorn Sheep occurs in fall between July and December, and their off-springs are born between January and June. The Baja 1000 Race takes place in November, disturbing this natural cycle for the already endangered species.

Noisy rally vehicles and spectators, helicopters flying overhead, trash, destroyed fences placed, vehicles illegally getting off the established route to gain time, and cactus burning are some of the information that by word of mouth was given to us by the affected land owners.

\section{Recommendations}

We recommend a more thorough study of the Ecological Impacts and an Impact assessment of the complete route taken by the Baja Racing participants. In addition, we suggest that each participant carry a GPS system which will be turned in to the judges and analyzed immediately after the race so they can assure the competitors stayed on track. We believe this alone could make a significant improvement on the environmental effects of the competition.

Information should be exchanged directly between the affected land owners and the Race Organizers.

\section{References}

[1] CONAP (2002). Plan de Manejo del Area de Protección de Flora y Fauna del Valle de los Cirios (document no publicado). Ensenada, B. C. SEMARNAP. 
454 Sustainable Tourism IV

[2] Estudio de impacto ambiental para la realización de las carreras fuera de carretera en el Estado de Baja California. Retrieved February 10, 2010 from http://www.descubrebajacalifornia.com/files/estudios/iacfc.pdf.

[3] Elizabeth Vargas (2008, November 13). Ejidos se agrupan y dicen NO a la Baja 1000. Periódico El Vigía. 